\title{
Photosensitizer Loaded Nano-Graphene for Multimo- dality Imaging Guided Tumor Photodynamic Therapy
}

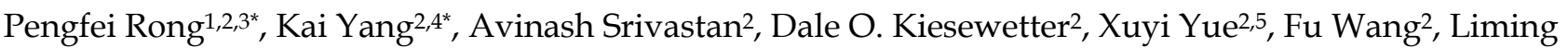

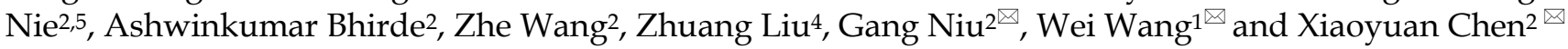 \\ 1. Department of Radiology, The Third Xiangya Hospital, Central South University, Changsha, Hunan 410013, China \\ 2. Laboratory of Molecular Imaging and Nanomedicine (LOMIN), National Institute of Biomedical Imaging and Bioengineering (NIBIB), National \\ Institutes of Health (NIH), Bethesda, Maryland 20892, United States \\ 3. State Key Laboratory for Powder Metallurgy, Central South University, Changsha, Hunan, 410083, China \\ 4. Institute of Functional Nano \& Soft Materials (FUNSOM), Soochow University, Suzhou, Jiangsu 215123, China \\ 5. Center for Molecular Imaging and Translational Medicine, School of Public Health, Xiamen University, Xiamen, Fujian 361102, China \\ * These authors contributed equally to this work.
}

$\square$ Corresponding authors: niug@mail.nih.gov (G. Niu); cjr.wangwei@vip.163.com (W. Wang), or shawn.chen@nih.gov (X. Chen).

(c) Ivyspring International Publisher. This is an open-access article distributed under the terms of the Creative Commons License (http://creativecommons.org/ licenses/by-nc-nd/3.0/). Reproduction is permitted for personal, noncommercial use, provided that the article is in whole, unmodified, and properly cited.

Received: 2013.1I.06; Accepted: 2013.12.01; Published: 2014.0I.15

\begin{abstract}
Graphene, a 2-dimensional carbon nanomaterial, has attracted wide attention in biomedical applications, owing to its intrinsic physical and chemical properties. In this work, a photosensitizer molecule, 2-(I-hexyloxyethyl)-2-devinyl pyropheophorbide-alpha (HPPH or Photochlor () ), is loaded onto polyethylene glycol (PEG)-functionalized graphene oxide (GO) via supramolecular ח-ח stacking. The obtained GO-PEG-HPPH complex shows high HPPH loading efficiency. The in vivo distribution and delivery were tracked by fluorescence imaging as well as positron emission tomography (PET) after radiolabeling of $\mathrm{HPPH}$ with ${ }^{64} \mathrm{Cu}$. Compared with free HPPH, GO-PEG-HPPH offers dramatically improved photodynamic cancer cell killing efficacy due to the increased tumor delivery of HPPH. Our study identifies a role for graphene as a carrier of PDT agents to improve PDT efficacy and increase long-term survival following treatment.
\end{abstract}

Key words: Graphene oxide, HPPH, photodynamic therapy, positron emission tomography, optical imaging.

\section{Introduction}

Photodynamic therapy (PDT) is an FDA approved modality for the local treatment of a variety of oncological, cardiovascular, dermatological, and ophthalmic diseases [1]. PDT utilizes reactive oxygen species (ROS) produced from light sensitive photosensitizer (PS) molecules, under suitable irradiation conditions, to induce cytotoxicity [2]. Compared with chemotherapy or radiotherapy, PDT shows relatively minimal side effects and improved tumor specific killing [3]. The need to achieve highly efficient delivery of photosensitizers to the tumor site in order to achieve better tumor response has been an intense focus in this field [4-8]. Approaches such as conjugating a receptor ligand or antibody to a photosensi- tizer to improve tumor selectivity have been many and largely disappointing. Often the number of ligands required has to be in excess to the number of receptors to achieve optimum dosage, limiting the use of targeted photosensitizers for PDT treatments [9, 10]. With high loading and delivery capability, nanoplatforms have been investigated as potential delivery vehicles for a number of photosensitizers such as pthalocyanines, porphyrins and others [11-15]. Nanoparticles offer several advantages: (i) a large surface area; (ii) easily modifiable surface chemistry for loading different agents; and (iii) tunable size for easy accumulation within tumor sites through the enhanced permeability and retention effect (EPR). 
Gold nanostructures, polymeric materials such as chitosan, PLGA, PAA, lipid based nanomaterials have been used as carriers for photosensitizers. For example, Chen et al. utilized newly synthesized gold vesicles loaded with chlorin e6 (Ce6) as dual photothermal/photodynamic therapeutic agents [15]. Zheng and colleagues reported the use of lipid enclosed nanostructures called porphysomes for dual modality imaging of tumors through optical as well as photoacoustic tomography [16]. Recently Ce6 was loaded onto the surface of graphene via п-п stacking and hydrophobic interactions for PDT of cancer cells $[17,18]$.

2-(1-Hexyloxyethyl)-2-devinyl pyropheophorbide-alpha (HPPH, Photochlor $\left.{ }^{\circledR}\right)$ is a second generation photosensitizer, currently progressing through phase I/II clinical trials, having a peak absorbance at $665 \mathrm{~nm}$ and has shown excellent safety and efficacy for the treatment of lung, Barrett's esophageal and head and neck cancers [19, 20]. More importantly, HPPH has been found to be safe for use in patients as a PDT agent, demonstrating significantly lower skin photo-toxicity compared to another porphyrin-based agent, Photofrin ${ }^{\circledR}[19,21]$. HPPH is also more tumor selective and shows faster clearance (20-26 hours plasma half-life) compared to Photofrin ${ }^{\circledR}$.

As single-layered carbon atoms packed into a two-dimensional (2D) honeycomb lattice, graphene has attracted extensive attention in many different fields including biomedical applications since its discovery in 2004 [17, 22-32]. The high specific surface area allows graphene to be used as carrier for both drug and gene delivery [18, 24, 33-36]. Owing to their intrinsic high near-infrared (NIR) absorbance, functionalized graphene oxide (GO) and reduced graphene oxide (rGO) have also been used as photothermal agents for in vivo cancer treatment [28, 37, 38]. Although pristine graphene or GO without surface coating has been reported to induce lung toxicity in mice when delivered orally or through intravenous injection [39], Liu and co-workers found that surface functionalized GO and rGO, coated with biocompatible materials such as PEG and other polymers are non-toxic to cells in vitro and can be cleared from mice via both renal and hepatic routes when introduced in vivo with various routes of administration $[40,41]$.

In this work, we developed a novel nanoformulation with graphene as the carrier and $\mathrm{HPPH}$ as the photosenstizer to treat xenograft tumors with PDT. To achieve this, PEG functionalized graphene (GO-PEG) is loaded with HPPH to form GO-PEG-HPPH complex via п-п stacking. GO-PEG-HPPH dramatically increased intracellular delivery of HPPH compared with free HPPH. In vivo fluorescence imaging and PET imaging with ${ }^{64} \mathrm{Cu}$ labeled $\mathrm{HPPH}$ revealed higher tumor uptake of GO-PEG-HPPH than free HPPH after intravenous administration. Irradiating the tumor with low power $671 \mathrm{~nm}$ laser after intravenous injection of GO-PEG-HPPH achieved significant tumor destruction. This graphene based nanoformulation showed great potential for HPPH delivery and imaging guided PDT.

\section{Materials and Methods}

\section{Synthesis of GO-PEG}

GO-PEG was synthesized following the procedure reported previously [28, 34, 35]. In brief, GO was prepared from graphite as an original material based on a modified Hummer's method. $\mathrm{NaOH}(0.05 \mathrm{M})$ was added to the GO suspension for about $4 \mathrm{~h}$ at $50{ }^{\circ} \mathrm{C}$ under stirring. The solution was adjusted to $\mathrm{pH}=1$ using $\mathrm{HCl}$. The resulting solution was neutralized and purified by repeated rinsing and centrifugation. A solution of mPEG-NH $2(5 \mathrm{mg} / \mathrm{ml})$ was added into the GO solution $(1 \mathrm{mg} / \mathrm{ml})$, and the mixture was sonicated for $5 \mathrm{~min} .5 \mathrm{mg}$ of N-(3-dimethylaminopropylN-ethylcarbodiimide) hydrochloride (EDC, from Sigma.) was then added to the mixture in two equal portions. The reaction was stirred overnight at room temperature, yielding a GO-PEG solution. The solution was further purified with dialysis and stored at $4{ }^{\circ} \mathrm{C}$ for further use.

\section{Synthesis of GO-PEG-HPPH}

$\mathrm{HPPH}$ was dissolved in DMSO as the stock solution. $4 \mathrm{mg}$ of HPPH was mixed with GO-PEG (2 $\mathrm{mg}$ ) in $1 \%$ Tween-20/water solution $(1 \mathrm{~mL})$, and stirred overnight at the room temperature. Excess HPPH was removed by centrifuge filtration through Amicon centrifugal filters (Millipore) with $100 \mathrm{kDa}$ molecular weight cutoff (MWCO) and washed with distilled water for 4-5 times. GO-PEG-HPPH complex was stored at $4{ }^{\circ} \mathrm{C}$ for further use.

\section{Characterization of GO-PEG-HPPH}

The absorbance at $680 \mathrm{~nm}$ was used as the characterization peak to confirm successful conjugation of $\mathrm{HPPH}$. The concentration of HPPH loaded on GO-PEG was determined by the characteristic absorption peak of HPPH at $680 \mathrm{~nm}$ with a molar extinction coefficient of $2.9 \times 10^{4} \mathrm{M}^{-1} \mathrm{~cm}^{-1}$ after subtracting the absorbance contributed by GO-PEG at the same wavelength. Fluorescence intensity of the GO-PEG-HPPH and free HPPH were monitored with an F-7000 fluorescence spectrophotometer (Hitachi, Tokyo, Japan) under $414 \mathrm{~nm}$ excitation.

\section{The release of HPPH from GO-PEG-HPPH}

To measure the release of $\mathrm{HPPH}$ from GO-PEG-HPPH complex, GO-PEG-HPPH complex 
was incubated in $\mathrm{pH} 5$ and $\mathrm{pH} 7.4$ solution for different periods of time $(0,3,6,24$, and $48 \mathrm{~h})$, respectively. The amount of retained HPPH on GO-PEG was measured by UV-vis-NIR spectra after removal of detached HPPH by centrifugal filtration.

\section{Detection of singlet oxygen}

GO-PEG-HPPH was fixed at $1.0 \mu \mathrm{M} \mathrm{HPPH}$ equivalent concentrations. The solutions were irradiated with a $671 \mathrm{~nm}$ laser (diode-pumped solid-state laser system (LASERGLOW Technologies, Toronto, Canada, $75 \mathrm{~mW} / \mathrm{cm}^{2}$ ). SOSG was dissolved in water containing $2 \%$ methanol with the final concentration of $1.0 \mu \mathrm{M}$. SOSG fluorescence was measured with a Synergy II microplate reader (BioTek, VT) using an excitation wavelength of $494 \mathrm{~nm}$. The sample's singlet oxygen level was evaluated by the SOSG fluorescence enhancement compared with the background or control samples.

\section{Cell uptake assay}

The 4T1 murine breast cancer cell line was obtained from American Type Culture Collection (ATCC, Manassas, VA). The cells were cultured in RPMI-1640 medium supplemented with 10\% FBS (GIBCO, Grand Island, NY) and $1 \%$ penicillin/streptomycin $(100 \mathrm{mg} / \mathrm{ml})$ solution at $37^{\circ} \mathrm{C}$ and $5 \% \mathrm{CO}_{2}$. For cell uptake assay, the cells were plated in Lab Tek II 8-well chamber slides (Nalge Nunc Internationl, Rochester, NY) with a density of $1 \times 10^{4}$ cells $/ \mathrm{ml}$ and grown to $60-80 \%$ confluency. Then the cells were incubated in the dark for $24 \mathrm{~h}$ with GO-PEG, GO-PEG-HPPH and free HPPH at the same $\mathrm{HPPH}$ concentration of $1 \mu \mathrm{M}$. The cells were then washed with $1 \times$ phosphate buffered saline (PBS) three times. Images were acquired by an IX81 epifluorescence microscope (Olympus, Hamburg, Germany).

\section{Flow cytometry}

The cells were incubated with GO-PEG, GO-PEG-HPPH, or free HPPH at the same HPPH concentration of $1 \mu \mathrm{M}$ for $24 \mathrm{~h}$. The cells were then washed and resuspended in PBS. The cells were measured by Accuri C6 flow cytometer using C Flow Plus software (BD, Ann Arbor, MI). The data were analyzed by FlowJo version 7.6.5 (FlowJo, Ashland, $\mathrm{OR})$.

\section{Cell toxicity assay}

4T1 cells were cultured in 96-well cell culture plates at $1 \times 10^{4} /$ well for $24 \mathrm{~h}$ and then treated with GO-PEG-HPPH, free HPPH, or GO-PEG at a series of concentrations up to $20 \mu \mathrm{M}$ ). Then, $20 \mu \mathrm{l}$ of MTT solution $(5.0 \mathrm{mg} / \mathrm{ml})$ was added to each well. After the 4 $\mathrm{h}$ incubation with the MTT, the media were removed and $100 \mu$ of dimethyl sulfoxide (DMSO) was added to solubilize the formazan crystals. The cell toxicity efficacy was measured with a microplate reader (Synergy II, BioTek, VT) at an absorbance of $570 \mathrm{~nm}$.

\section{In vitro PDT}

$4 \mathrm{~T} 1$ cells were plated in 96-well plates at a density of $5 \times 10^{3}$ cells/well in RPMI-1640 complete media. The cells were incubated with GO-PEG, GO-PEG-HPPH, or free HPPH at the same HPPH concentration of $1 \mu \mathrm{M}$ for $24 \mathrm{~h}$. The wells were then washed with PBS three times. $100 \mu \mathrm{l}$ of fresh medium was added into each cell, which were immediately irradiated by the $671 \mathrm{~nm}$ laser at various fluence rates $\left(2-8 \mathrm{~mW} / \mathrm{cm}^{2}\right)$ for $3 \mathrm{~min}$. The plates were kept in the incubator overnight for further cultivation. Cell viability was estimated by the standard MTT assay as described above.

\section{Animal model}

Athymic nude mice were obtained from Harlan laboratories (Frederick, USA) under protocols approved by the National Institutes of Health Clinical Center Animal Care and Use Committee (NIH CC/ACUCC). The 4T1 tumor models were generated by subcutaneous injection of $1 \times 10^{6}$ cells in $100 \mu \mathrm{PBS}$ into the right shoulder of nude mice. The mice were used for imaging and photodynamic therapy when the tumor volume reached $100 \mathrm{~mm}^{3}$ (5-7 days for 4T1).

\section{In vivo fluorescence imaging of GO-PEG-HPPH}

Mice bearing 4T1 xenografted tumors were intravenously injected with GO-PEG-HPPH, free $\mathrm{HPPH}$ or GO-PEG $(200 \mu \mathrm{l}, 1 \mathrm{mg} / \mathrm{kg}$ for HPPH, $0.77 \mathrm{mg} / \mathrm{kg}$ for GO-PEG). Fluorescence imaging was performed with a Maestro II optical imaging system (Caliper Life Sciences, Hopkinton, MA) at 0.5, 1, 2, 6, 24, 36, and 72 $\mathrm{h}$ post-injection. The HPPH spectrum was separated from autofluorescence by Maestro II software (Caliper Life Sciences).

\section{${ }^{64} \mathrm{Cu}$ labeling of HPPH}

The copper labeling of HPPH was performed according to the procedure reported previously with modification [42]. HPPH $(50 \mu \mathrm{g})$ was dissolved in DMSO $(50 \mu \mathrm{l})$ and then buffered with sodium acetate $(200 \mu \mathrm{l}, 0.1 \mathrm{M}, \mathrm{pH}$ 5.5). Then ethanol $(200 \mu \mathrm{l})$ was added. Into the solution, ${ }^{64} \mathrm{Cu}(1 \mathrm{mCi})$ in sodium acetate buffer $(\mathrm{pH} 5.5,75 \mu \mathrm{l})$ was added. The mixture was heated to $100{ }^{\circ} \mathrm{C}$ for $30 \mathrm{~min}$. The labeling efficiency was determined by HPLC. After labeling, the reaction was neutralized with 10× PBS and mixed with cold $\mathrm{HPPH}$. Half of the product was used to prepare GO-PEG- $\left[{ }^{64} \mathrm{Cu}\right] \mathrm{HPPH}$ according to the procedure mentioned above. 


\section{In vivo $P E T$ imaging}

PET imaging studies were conducted with Inveon microPET scanner (Siemens Preclinical Solution). Static PET images were acquired at $24 \mathrm{hr}$ after injection of $3.7 \mathrm{MBq}(100 \mu \mathrm{Ci}){ }^{64} \mathrm{Cu}$-labeled $\mathrm{HPPH}$ mixed with unlabeled HPPH $(200 \mu \mathrm{g})$ or GO-PEG-HPPH via the tail vein $(n=4$ /group). After 15 min of data acquisition, PET images were reconstructed with 3-dimensional ordered-subsets expectation maximum (3D OSEM) followed by maximum a posteriori (MAP) algorithm. Three dimensional regions of interest (ROIs) were drawn on tumor and main organs including liver and muscle using the Inveon Research Workplace (IRW) Software 4.0. The mean pixel values in the VOIs were then converted to the radioactivity in units of $\mathrm{MBq} / \mathrm{ml}$. The image derived tumor and tissue uptake, which is percent injected dose per gram $(\% \mathrm{ID} / \mathrm{g})$, were obtained with tumor and tissue radioactivity divided by injected dose assuming the tumor and tissue density are 1 $\mathrm{g} / \mathrm{cm}^{3}$.

To further confirm PET image quantification results, the mice in both groups were euthanized immediately after imaging. Blood, tumor and main organs were harvested, wet weighed and measured by a gamma counter (Wallac Wizard 1470, PerkinElmer Inc.). The radioactivity was expressed as percentage of injected dose per gram $(\% \mathrm{ID} / \mathrm{g}$, mean $\pm \mathrm{SD}$, $\mathrm{n}=4$ /group) .

\section{In vivo photoacoustic imaging}

When the tumor size reached $\sim 100 \mathrm{~mm}^{3}$, GO-PEG-HPPH $(200 \mu \mathrm{l}, 1.0 \mathrm{mg} / \mathrm{kg} \mathrm{HPPH}$ and 0.77 $\mathrm{mg} / \mathrm{kg}$ of GO-PET), GO-PEG $(0.77 \mathrm{mg} / \mathrm{kg})$, or free $\mathrm{HPPH}(1.0 \mathrm{mg} / \mathrm{kg})$ were injected via tail vein. Twenty-four hrs later, the tumor region was exposed to 20 min of laser irradiation at $671 \mathrm{~nm}, 90 \mathrm{~J} / \mathrm{cm}^{2}, 75$ $\mathrm{mW} / \mathrm{cm}^{2}$. The oxygen saturation $\left(\mathrm{sO}_{2}\right)$ change in the tumor sites before and after PTT treatment was quantified by a photoacoustic (PA) imaging system (Vevo 2100, VisualSonics, Inc.) equipped with a $40 \mathrm{MHz}$ array linear transducer with 256 elements. A tunable OPO laser beam was delivered at $750 \mathrm{~nm}$ and $980 \mathrm{~nm}$ to compute $\mathrm{sO}_{2}$ according to the software provided by the manufacturer (VisualSonics).

\section{Photodynamic therapy}

When the tumor size reached $\sim 100 \mathrm{~mm}^{3}$, mice bearing 4T1 tumor were randomized into 6 groups. Mice in groups 1, 2 and 3 received an intravenous injection of GO-PEG-HPPH ( $\mathrm{n}=6,1.0 \mathrm{mg} / \mathrm{kg} \mathrm{HPPH}$ and $0.77 \mathrm{mg} / \mathrm{kg}$ GO-PEG), GO-PEG ( $\mathrm{n}=5,0.77$ $\mathrm{mg} / \mathrm{kg})$ or free HPPH $(\mathrm{n}=6,1.0 \mathrm{mg} / \mathrm{kg})$, followed by $20 \mathrm{~min}$ of laser irradiation $\left(671 \mathrm{~nm}, 90 \mathrm{~J} / \mathrm{cm}^{2}, 75\right.$ $\left.\mathrm{mW} / \mathrm{cm}^{2}\right)$ at $24 \mathrm{~h}$ post-injection. Mice in groups 4,5 and 6 were designated as the controls, each received an intravenous injection of drugs but without laser irradiation. Mice were monitored for up to 60 days post PDT treatment for tumor regrowth. Tumor size was monitored with a digital caliper every other day and tumor volume was calculated as vol $=a b^{2} / 2$, where $a$ is the longer diameter and $b$ is the shorter diameter. Mice were euthanized for ethical consideration when tumor volume reached $2000 \mathrm{~mm}^{3}$. On the other hand, mice were considered cured if there was no palpable tumor by day 60 . The body weights of all mice were measured every other day.

\section{Ex vivo histological staining}

Major organs were collected from the euthanized $4 \mathrm{~T} 1$ bearing mice at $24 \mathrm{~h}$ after PDT. Tissues were fixed in a $4 \%$ formaldehyde solution at room temperature for at least $48 \mathrm{hrs}$. Haematoxylin and eosin (H\&E) staining (BBC Biochemical, Mount Vernon, WA) was performed and observed with a BX41 bright field microscopy (Olympus).

\section{Statistical analysis}

The level of significance in all statistical analyses was set at a probability of $\mathrm{P}<0.05$. Data are presented as means \pm SD. Analysis of variance and tests was used to analyze the data.

\section{Results and Discussion}

\section{Synthesis and in vivo characterization}

GO was synthesized by a modified Hammer's method [28, 34, 35]. Amino-terminated PEG (5 kDa) was conjugated to GO via amide formation to form GO-PEG. HPPH, a PS agent, was loaded onto the surface of GO-PEG via ח-ח stacking (Figure 1a). Atomic force microscope (AFM) imaging showed that the size of GO-PEG was less than $50 \mathrm{~nm}$ and the thickness was $\sim 1.5 \mathrm{~nm}$. After loading $\mathrm{HPPH}$, the thickness of GO-PEG-HPPH increased to $\sim 2 \mathrm{~nm}$ (Figure $1 \mathrm{~b}$ \& Supplementary Material: Figure S1). GO-PEG exhibited excellent stability in a range of physiological solutions including water, PBS, cell medium, and fetal bovine serum (FBS) (Figure 1c). UV-vis-NIR spectrum showed characteristic absorption peaks of GO-PEG-HPPH at 414 and $665 \mathrm{~nm}$, suggesting successful loading of HPPH onto GO-PEG (Figure 1d). The UV-vis absorption peak at $665 \mathrm{~nm}$ was then used to determine the concentration of HPPH in GO-PEG-HPPH complex after subtraction of absorbance contributed by GO-PEG (Supplementary Material: Figure S2a). A loading efficiency of $131 \%$ (HPPH: GO-PEG weight ratio) was achieved in a reaction of $4 \mathrm{mg}$ of HPPH mixed with $2 \mathrm{mg}$ of GO-PEG.

In order to understand the interaction between GO-PEG and HPPH, fluorescence spectra of 
GO-PEG-HPPH and free HPPH were recorded (Figure 1e). HPPH fluorescence was quenched once it was loaded onto GO-PEG, likely owing to the direct contact between $\mathrm{HPPH}$ and the graphene sheet. The generation of singlet oxygen $\left({ }^{1} \mathrm{O}_{2}\right)$ of GO-PEG-HPPH and free $\mathrm{HPPH}$ were detected using the singlet oxygen sensor green (SOSG) as a detector with $671 \mathrm{~nm}$ excitation. The SOSG's fluorescence intensity from both GO-PEG-HPPH and free HPPH exhibits an exposure time-dependent enhancement, indicating increased ${ }^{1} \mathrm{O}_{2}$ generation (Supplementary Material: Figure S3). Although the fluorescence of HPPH was significantly quenched by GO-PEG, the ${ }^{1} \mathrm{O}_{2}$ generation ability of GO-PEG-HPPH was $\sim 60-70 \%$ relative to that of free HPPH (Figure 1f), which allows application of GO-PEG-HPPH for PDT of tumors. One advantage of nanoformulation lies in increased intracellular and intratumoral delivery [35], by which the decreased ${ }^{1} \mathrm{O}_{2}$ generation of GO-PEG-HPPH could be compensated.

\section{In vitro PDT}

Therefore, we investigated the cellular uptake of GO-PEG-HPPH and free HPPH with 4T1 murine mammary cancer cells. The cells were incubated with GO-PEG-HPPH and free HPPH at equivalent HPPH

(a)
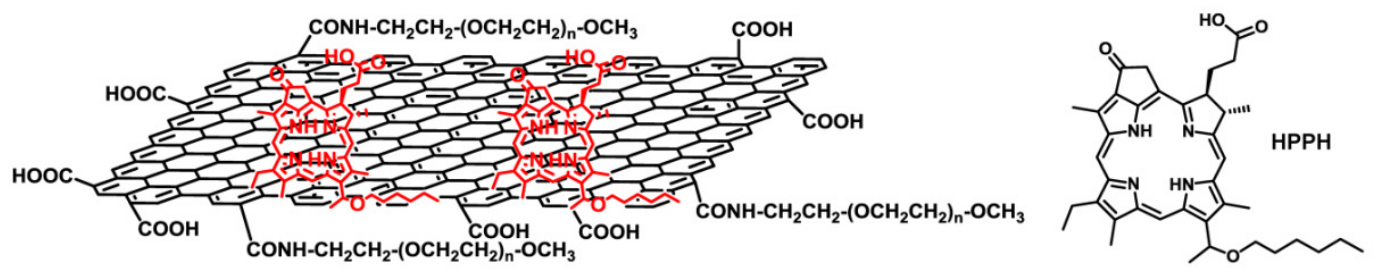

(b)

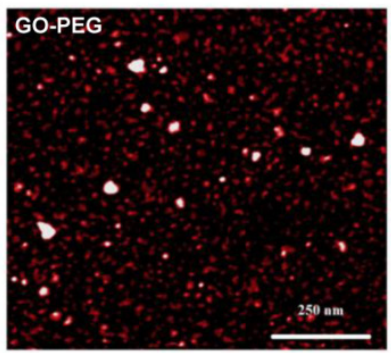

(d)

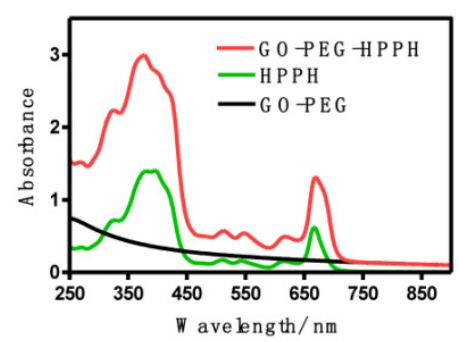

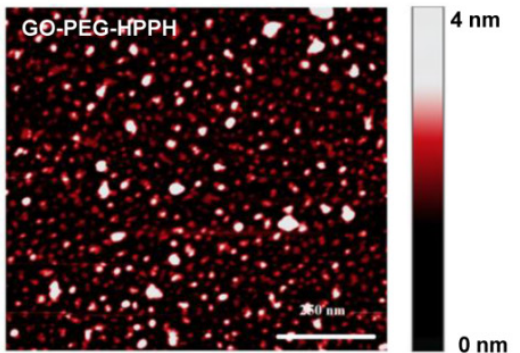

(e)

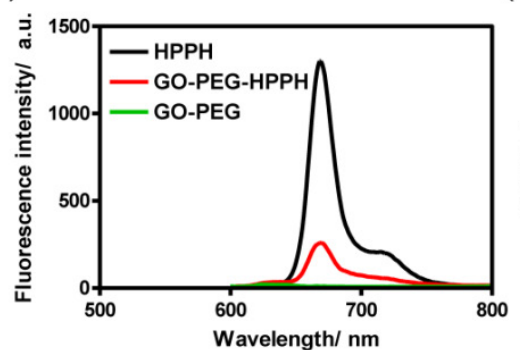

(c)

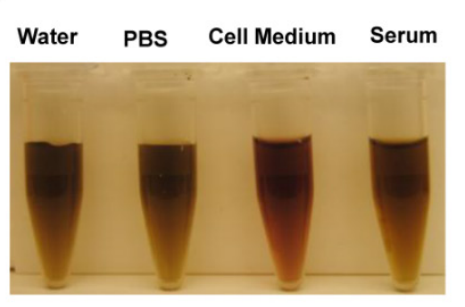

(f)

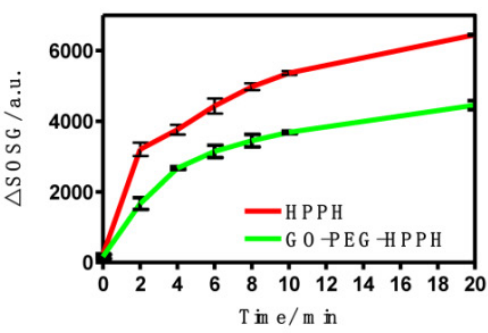

Figure I. a) Schematic structure of GO-PEG-HHPH. b) AFM images of GO-PEG and GO-PEG-HPPH dispersed in ultra-pure water. Scale bar: 250 nm. c) Stability of GO-PEG-HPPH in water, PBS, cell medium and serum. No precipitation was observed at $24 \mathrm{~h}$ after incubation. d) Normalized UV-vis spectra of GO-PEG, HPPH and GO-PEG-HPPH. Two characteristic absorption peaks at 414 and $665 \mathrm{~nm}$ were observed for GO-PEG-HPPH. e) Fluorescence spectra of free HPPH, GO-PEG and GO-PEG-HPPH at a concentration of I $\mu$ M of HPPH and $0.49 \mu \mathrm{g}$ of GO-PEG. $f$ ) Singlet oxygen generation of free HPPH and GO-PEG-HPPH (I $\mu$ M) after irradiation with $67 \mathrm{Im}$ laser $\left(75 \mathrm{~mW} / \mathrm{cm}^{2}\right)$ for different periods of time. 
(a)

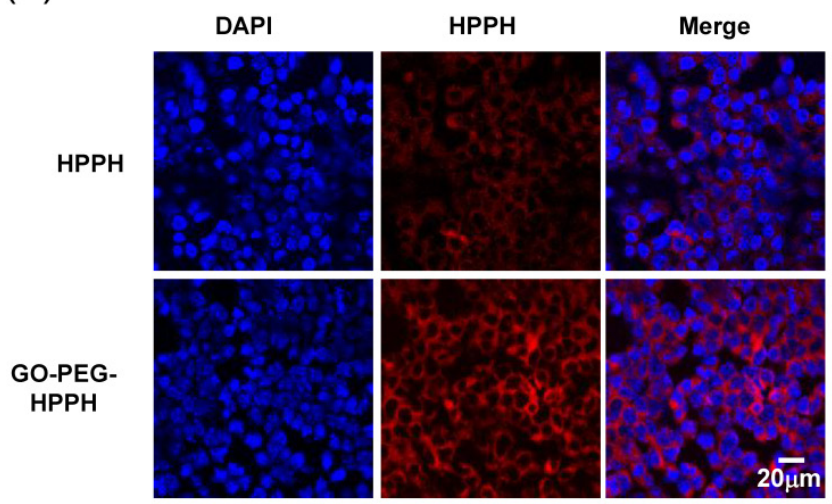

(c)

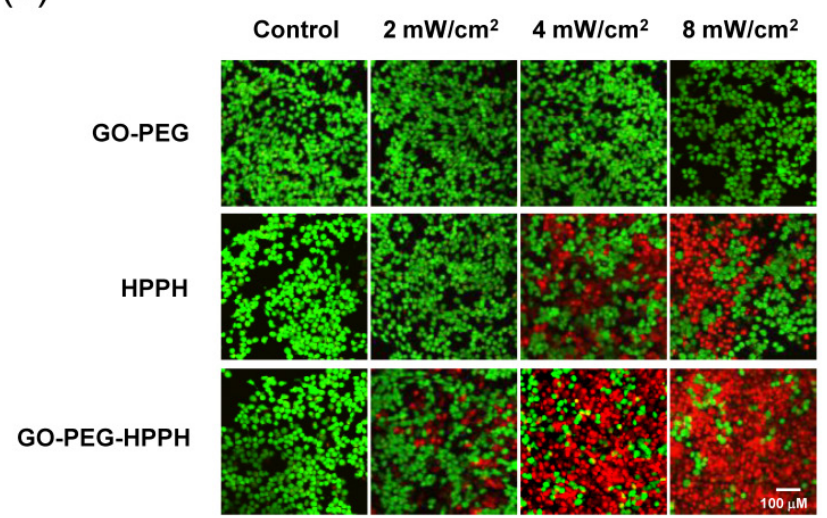

(b)

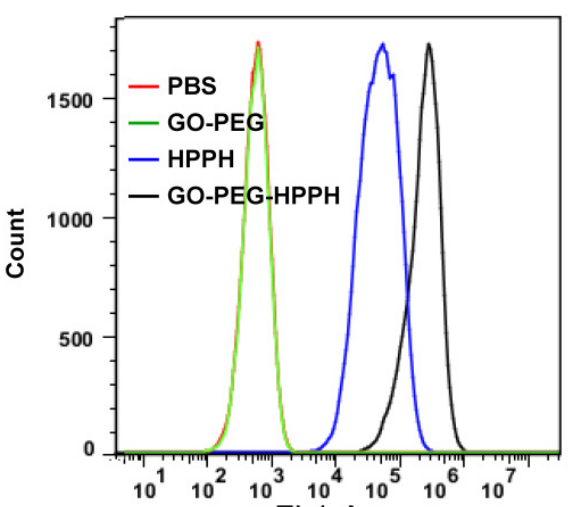

(d)

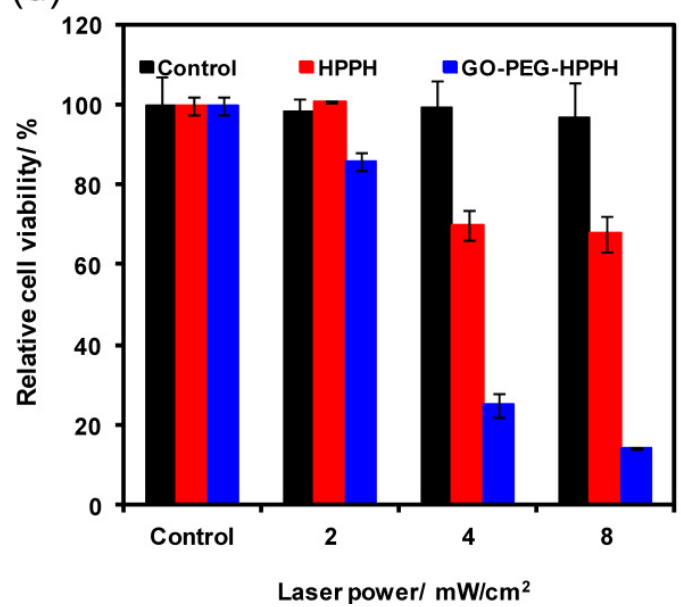

Figure 2. a) Fluorescence image of $4 \mathrm{TI}$ cells incubated with $0.49 \mu \mathrm{g} / \mathrm{ml}$ GO-PEG, I $\mu \mathrm{M}$ free HPPH or equivalent amount of GO-PEG-HPPH (I $\mu M$ HPPH and 0.49 $\mu \mathrm{g} / \mathrm{ml}$ GO-PEG) after $24 \mathrm{~h}$. Scale bars, $20 \mu \mathrm{m}$. b) Flow cytometric analysis of mean fluorescence intensity $(n=10,000$ cells) in 4TI cells incubated with PBS (red), 0.49 $\mu \mathrm{g} / \mathrm{ml}$ GO-PEG (green), I $\mu \mathrm{M}$ HPPH (blue), and GO-PEG-HPPH (black) for 24 h. c) Fluorescence image of Calcein AM/Ethidium homodimer-I stained 4TI cells incubated with I $\mu \mathrm{M}$ free HPPH, $0.49 \mu \mathrm{g} / \mathrm{ml}$ GO-PEG or GO-PEG-HPPH for $24 \mathrm{~h}$ after laser irradiation $\left(67 \mathrm{lmm}, 2-8 \mathrm{~mW} / \mathrm{cm}^{2}, 3 \mathrm{~min}\right)$. Scale bars: I00 $\mu \mathrm{m}$. d) Relative viability of 4 TI cells incubated with various concentrations of free HPPH, GO-PEG, GO-PEG-HPPH after irradiation by $671 \mathrm{~nm}$ laser $\left(2-8 \mathrm{~mW} / \mathrm{cm}^{2}, 3 \mathrm{~min}\right)$.

The next sets of experiments were performed to analyze the in vitro phototoxicity of the GO-PEG $\mathrm{HPPH}$ as compared to free HPPH. 4T1 cancer cells were incubated with GO-PEG, free HPPH or GO-PEG-HPPH at $1 \mu \mathrm{M}$ equivalent of HPPH and 0.49 $\mu \mathrm{g} / \mathrm{ml}$ of GO-PEG for $24 \mathrm{~h}$. Without laser irradiation, no cytotoxicity of either GO-PEG alone, free HPPH or GO-PEG-HPPH was observed following incubation, as determined by MTT assay (Supplementary Material: Figure S5). With $4 \mathrm{~mW} / \mathrm{cm}^{2} 671 \mathrm{~nm}$ laser irradiation for $3 \mathrm{~min}$, cells treated with GO-PEG-HPPH exhibited significantly higher cell death than that of free $\mathrm{HPPH}$, as shown by Calcein/Propidium iodide staining to distinguish the live cells (green color) and dead cells (red color). It has been reported that GO has mild photothermal conversion ability under irradiation of an $808 \mathrm{~nm}$ laser [45]. However, the cells treated with GO-PEG showed negligible cell death, indicating the mechanism of cytotoxicity was through photodynamic action (Figure 2c). It is reasonable since we used very low concentration of GO plus low laser power. GO-PEG-HPPH showed more toxicity to cells than free HPPH and GO-PEG at equivalent concentrations under irradiation by the same laser power density (Figure $2 \mathrm{~d}$ ). The relative cell viability is significantly lower for cells treated with GO-PEG-HPPH $(14.22 \pm 0.28 \%)$ than that treated with free HPPH $(67.72 \pm 4.35 \%, \mathrm{P}<0.01)$ and GO-PEG $(96.73 \pm 8.81 \%$, $\mathrm{P}<0.01)$.

\section{In vivo HPPH delivery and PDT}

For in vivo studies, we first investigated the tumor accumulation profile of GO-PEG-HPPH and free HPPH in 4T1 tumor-bearing mice with both fluorescence and PET imaging. Compared with free HPPH, GO-PEG-HPPH demonstrated significantly higher fluorescence signal within the tumor region (Figure 3a). Since PDT is usually performed at $24 \mathrm{~h}$ after HPPH injection [44], another group of tumor-bearing mice were euthanized at $24 \mathrm{~h}$ p.i. and the major organs and tumors were collected for ex vivo optical imaging. Very strong fluorescence intensity within tumors was observed, while the organs such as liver and spleen showed very weak fluorescence intensity 
(Figure 3b), which might indicate high tumor selectivity. These results demonstrated high tumor accumulation and release of HPPH through GO-PEG as the carrier. However, the optical imaging may not reflect accurately the pharmacokinetics of GO-PEG-HPPH and free HPPH since it is very difficult to establish a linear correlation between $\mathrm{HPPH}$ concentration and fluorescence intensity. Moreover, according to our previous studies, the images do not accurately reflect the liver and spleen uptake of the GO-PEG-HPPH. As liver and spleen are pigmented and light-absorbing, direct fluorescence measurement of photosensitizer distribution in these organs is thus of limited value [28].

To accurately determine the accumulation profile of the GO-PEG-HPPH relative to free $\mathrm{HPPH}$, we labeled HPPH with a positron emitting radioisotope, copper-64 $\left({ }^{64} \mathrm{Cu}, \mathrm{t}_{1 / 2}=12.7 \mathrm{~h}\right.$ ) (Supplementary Materi- al: Figure S6). Then ${ }^{64} \mathrm{Cu}$ labeled HPPH $\left({ }^{64} \mathrm{Cu}-\mathrm{HPPH}\right)$ was loaded onto the surface of GO-PEG along with the unlabeled HPPH to match the therapy dose (1 $\mathrm{mg} / \mathrm{kg}$ ). Different from the results of the optical imaging, PET images showed high accumulation of both GO-PEG- $\left[{ }^{64} \mathrm{Cu}\right] \mathrm{HPPH}$ and $\left[{ }^{64} \mathrm{Cu}\right] \mathrm{HPPH}$ in the liver at $24 \mathrm{~h}$ p.i. (Figure 3c). Compared with $\left[{ }^{64} \mathrm{Cu}\right] \mathrm{HPPH}$, GO-PEG- $\left[{ }^{64} \mathrm{Cu}\right] \mathrm{HPPH}$ showed significantly higher tumor uptake $(3.11 \pm 0.20$ vs. $1.28 \pm 0.35 \% \mathrm{ID} / \mathrm{g}, \mathrm{P}<$ $0.01)$ and lower liver uptake (26.86 \pm 4.76 vs. $36.72 \pm$ $6.70 \% \mathrm{ID} / \mathrm{g}, \mathrm{P}<0.05$ ) (Figure 3d). Following PET imaging studies, animals were euthanized and the major organs and tumors were collected to measure the radioactivity with a gamma counter. Consistent with PET imaging, other than tumor accumulation, majority of the remaining radioactivity was observed in the liver and spleen (Figure 3e). (a)

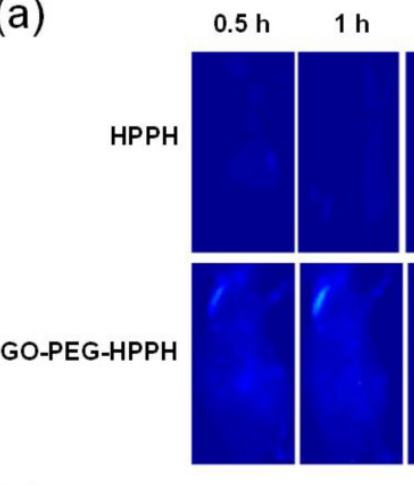

(c)

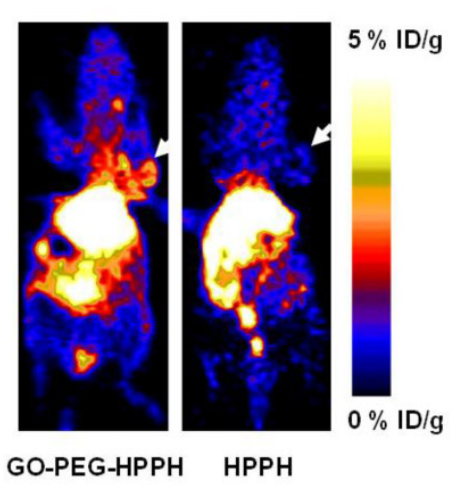

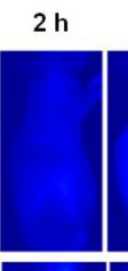
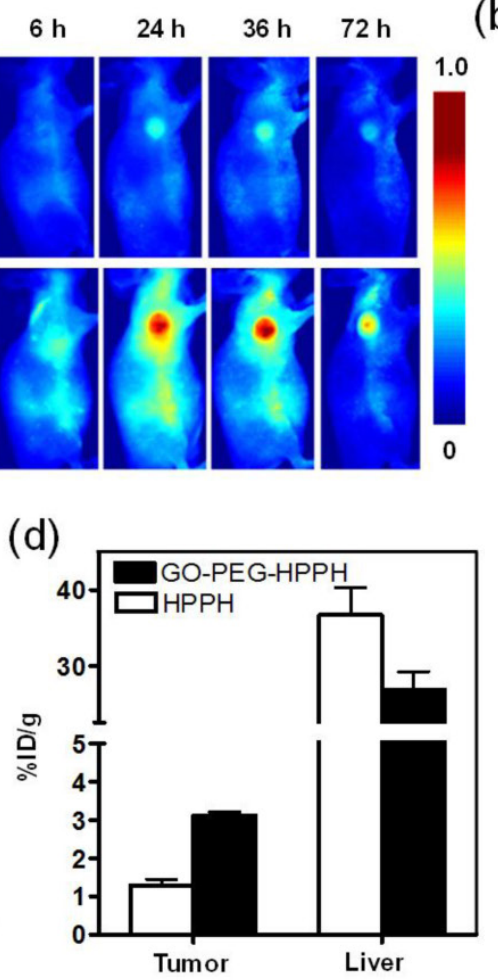

(b)

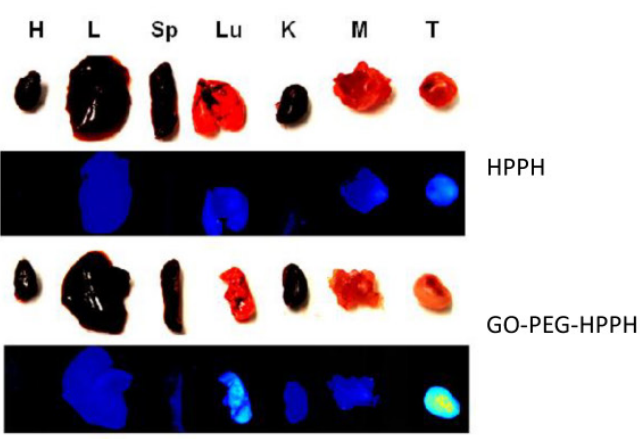

(e)

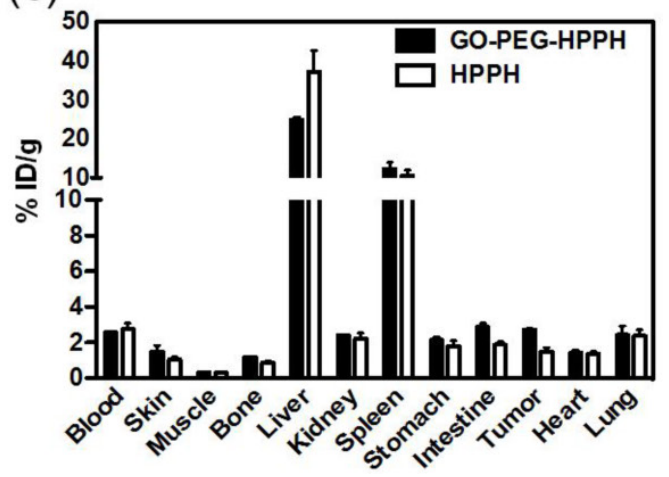

Figure 3. a) In vivo near-infrared (NIR) fluorescence imaging evaluation of distribution and tumor delivery of HPPH and GO-PEG-HPPH in 4TI tumor-bearing mice at different time points after injection. b) Ex vivo near-infrared (NIR) fluorescence imaging of tumor and major organs collected at $24 \mathrm{~h}$ after drug injection. $\mathrm{H}$, heart; L, liver; Sp, spleen; Lu, lung; K, kidney; M, muscle; T, tumor. c) Decay-corrected whole-body coronal microPET images of 4TI tumor-bearing mice at 24 h after injection of $3.7 \mathrm{MBq}(100 \mu \mathrm{Ci})$ of ${ }^{64} \mathrm{Cu}-\mathrm{HPPH}$ mixed with $\mathrm{HPPH}$ or ${ }^{64} \mathrm{Cu}-\mathrm{HPPH}$ loaded GO-PEG-HPPH. The tumors are indicated by arrows. d) Region of interest (ROI) analysis of tumor uptake of ${ }^{64} \mathrm{Cu}-\mathrm{HPPH}$ at I5, 30,60, and $120 \mathrm{~min}$ in $4 \mathrm{TI}$ tumor-bearing mice $(\mathrm{n}=6 / \mathrm{group})$ as derived from static microPET images. e) Ex vivo biodistribution of ${ }^{64} \mathrm{Cu}-\mathrm{HPPH}$ (3.7 MBq per mouse) in $4 \mathrm{TI}$ tumor bearing nude mice at $24 \mathrm{~h}$ time points. 
(a)

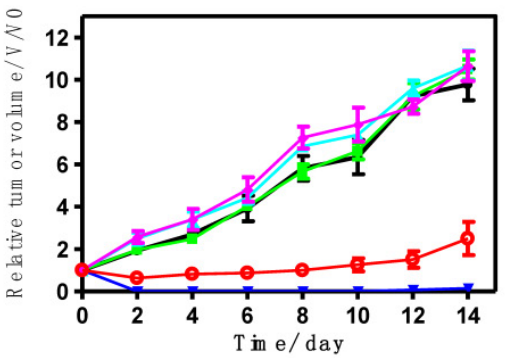

(b)

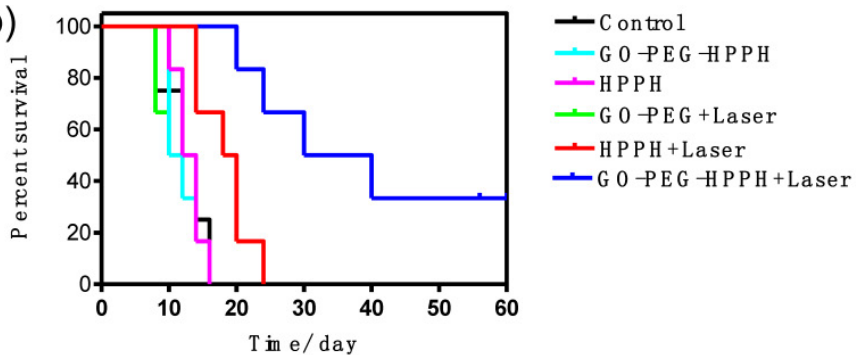

(c)

(d)
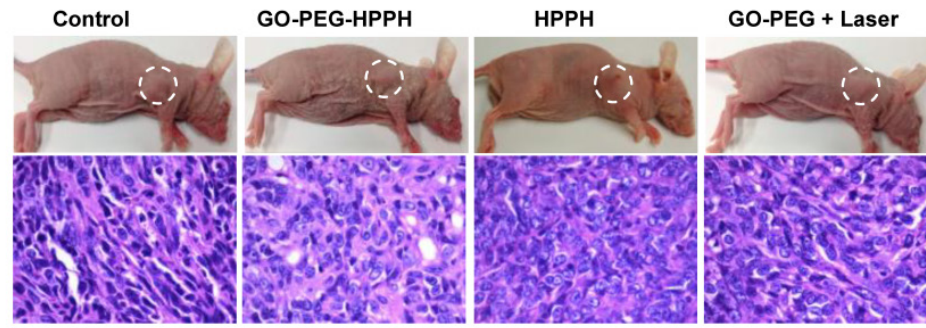

HPPH + Laser

GO-PEG-HPPH + Laser

(e)

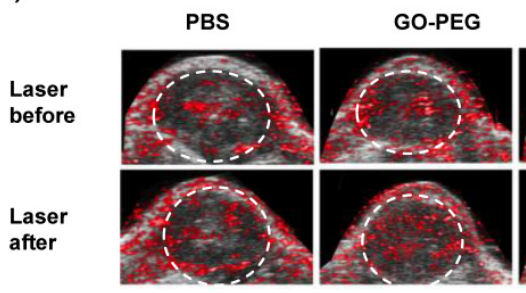

HPPH

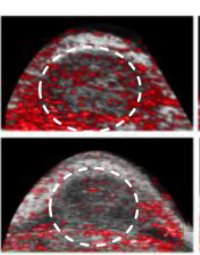

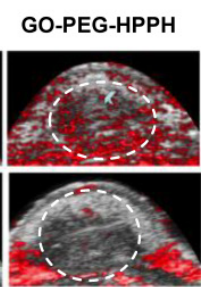

(f)
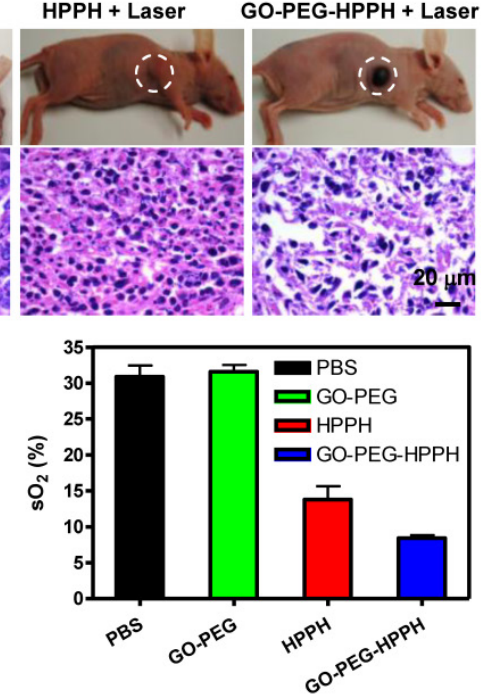

Figure 4. a) Tumor growth curves of different groups of tumor-bearing mice after treatment. The tumor volumes were normalized to their initial sizes. The error bars represent the standard deviations of 4-6 mice per group. $* *, p<0.05$. b) The Kaplan-Meier survival curves of different groups of tumor-bearing mice after treatment. c) Representative photos of $4 \mathrm{TI}$ tumor-bearing mice from different groups I4 days after treatment. The circles indicate the location of the tumors. $\mathrm{d}$ ) $\mathrm{H} \& \mathrm{E}$ stained tumor sections collected from different groups of mice $24 \mathrm{hr}$ post treatment. The GO-PEG-HPPH treated tumor was severely damaged after laser irradiation. e) Ultrasound and photoacoustic imaging of 4TI tumor-bearing mice before or $24 \mathrm{hr}$ after exposure to $67 \mathrm{Imm}$ laser (75 mW/cm², $20 \mathrm{~min}$ ). The laser irradiation was performed at $24 \mathrm{~h}$ post-injection of PBS, GO-PEG, HPPH, or GO-PEG-HPPH. The circles indicate the region of interest in the tumors. Scale bars: I mm. $f$ Quantitative analysis of fractional oxygen saturation of photoacousitc data.

We next carried out an in vivo PDT study with six groups of $4 \mathrm{~T} 1$ tumor mice (5-7 mice/group). For the treatment groups, $4 \mathrm{~T} 1$ tumor mice were intravenously injected with GO-PEG-HPPH or free HPPH at the same HPPH concentration $(1 \mathrm{mg} / \mathrm{kg})$ then irradiated at $24 \mathrm{~h}$ p.i. by the $671 \mathrm{~nm}$ laser at a power density of 75 $\mathrm{mW} / \mathrm{cm}^{2}$ for $20 \mathrm{~min}$. Tumors treated with GO-PEG-HPPH under irradiation were effectively ablated (Figure 4a\&c). For HPPH treated group with laser irradiation, the tumors were partially damaged and exhibited delayed tumor growth compared with the control groups (Figure 4a\&c). However, tumors in all the control groups showed similar growth speed, suggesting that neither laser irradiation alone nor GO-PEG, GO-PEG-HPPH or free HPPH injections without laser irradiation affected tumor development (Figure 4a\&c). Importantly, mice in the three control groups showed average life span of $\sim 16$ days, and mice treated with free HPPH and irradiation showed average life span of $\sim 24$ days. While in the group exposed to GO-PEG-HPPH injection plus laser irradiation, the mice demonstrated significantly longer life span of $\sim 40$ days (Figure $4 b$ ). The tumors from the treated mice were collected at $24 \mathrm{~h}$ after laser irradiation for hematoxylin and eosin (H\&E) staining. Tumor cells from GO-PEG-HPPH and laser irradiation treated group exhibited significantly more damage compared to tumors collected from the free $\mathrm{HPPH}$ and laser irradiation treated group. In the other control groups, negligible damage was observed (Figure 4d). We also used photoacoustic imaging (PAI) to monitor the average fractional oxygen saturation $\left(\mathrm{sO}_{2}\right)$ inside tumors before and after GO-PEG-HPPH and free HPPH injection and laser irradiation (Figure 4e). Compared with PBS and GO-PEG injected groups, average tumor $\mathrm{SO}_{2}$ was remarkably decreased in both free HPPH and GO-PEG-HPPH treated groups (Figure $4 \mathrm{f}$ ). These results showed that PDT with GO-PEG-HPPH significantly decreased the oxygen saturation of tumors, which can be evaluated by PAI.

Finally, we investigated the potential in vivo toxicity of GO-PEG-HPPH and free HPPH with an equivalent $\mathrm{HPPH}$ dose of $1 \mathrm{mg} / \mathrm{kg}(\mathrm{n}=6 /$ group$)$. We 
did not notice any obvious sign of toxic side effects and body weight drop of GO-PEG-HPPH and free $\mathrm{HPPH}$ plus laser treated groups (Figure 5a). We also collected the major organs including liver, spleen, kidney, heart, and lung from the mice of all groups. No noticeable signal of organ damage was observed from H\&E stained organ slices (Figure 5b), indicating that the GO-PEG based formula is safe to administer. However, our results were obtained after a single injection of therapeutic dose level of HPPH. Further toxicological studies are demonstrating the safety issue of GO-PEG are needed to determine the biocompatibility of GO-PEG as a potential carrier for photosensitizing agents.

(a)

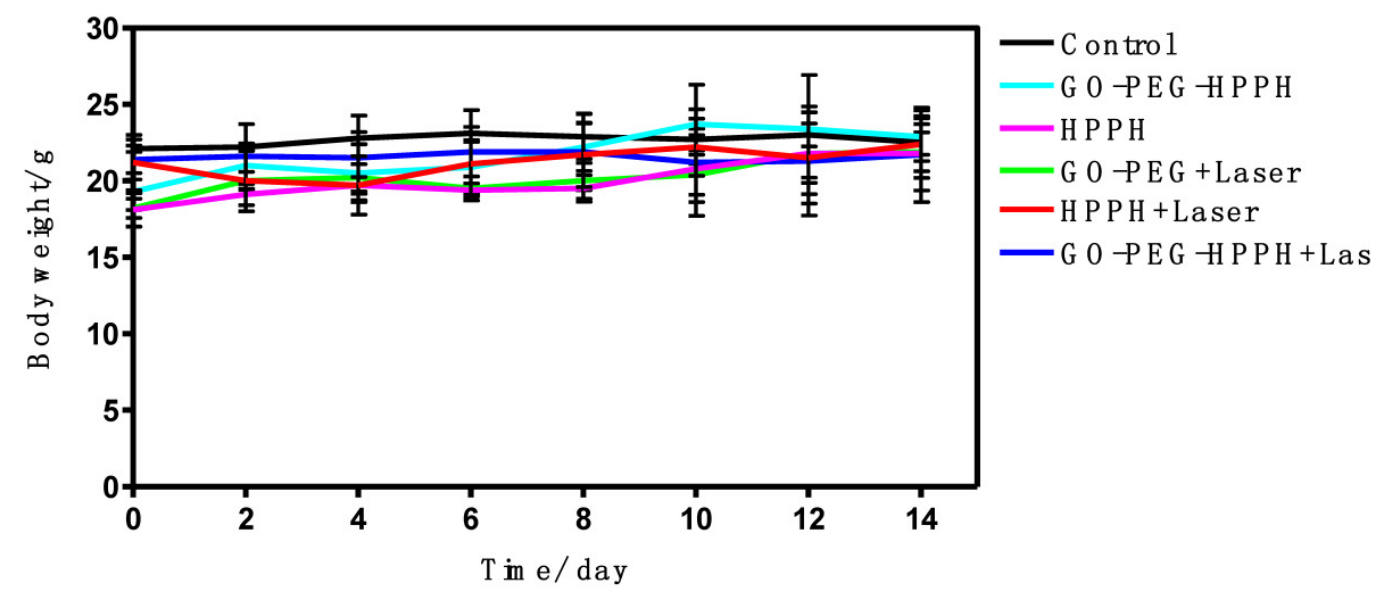

(b)

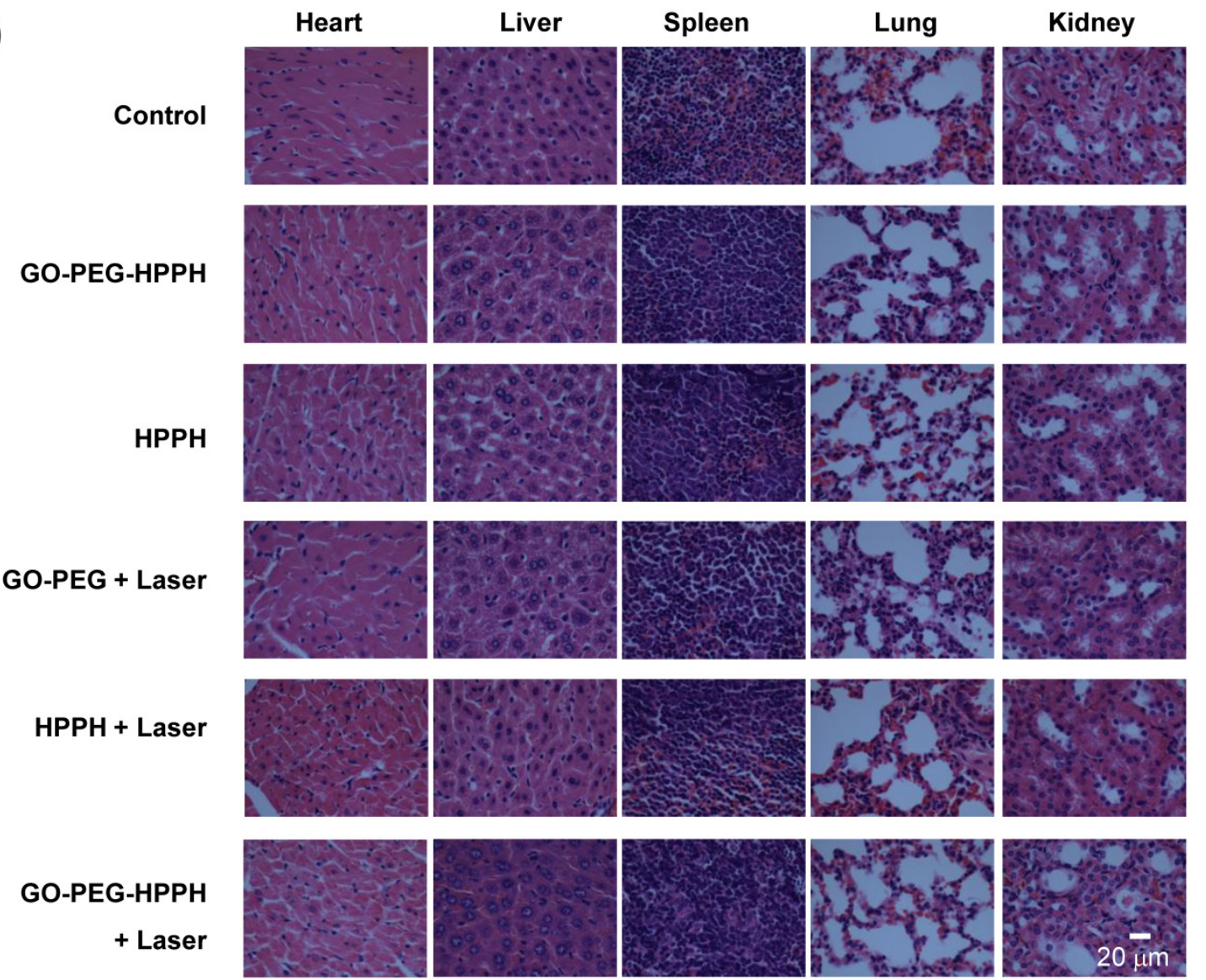

Figure 5. a) Body weight curve of $4 \mathrm{TI}$ tumor bearing mice after treatment. b) H\&E stained images of major organs. No noticeable abnormality was observed in major organs including liver, spleen, kidney, heart, and lung. 


\section{Conclusion}

We successfully developed a novel nanoformulation of GO-PEG loaded with photosensitizer HPPH for photodynamic therapy of tumors. Although GO-PEG-HPPH showed somewhat lower singlet oxygen generation efficiency compared to free $\mathrm{HPPH}$, it does offer dramatically improved photodynamic cancer cell killing efficacy in vivo due to the increased accumulation of HPPH to the tumor area and more effective tumor cell internalization of the photosensitizer, which is evidenced by high tumor signal on fluorescence imaging and PET imaging. Moreover, GO-PEG-HPPH induced more oxygen consumption within the tumor compared with free HPPH upon 671 $\mathrm{nm}$ laser irradiation. Our study identifies the role for graphene as a carrier of PDT agents to improve PDT efficacy and increase long-term survival of tumor mice following treatment. The results also suggest the potential of graphene based nanoformulations for clinical translation.

\section{Supplementary Material}

Figure S1-Figure S6.

http://www.thno.org/v04p0229s1.pdf

\section{Acknowledgment}

This work was supported by the Major State Basic Research Development Program of China (973 Program) (2013CB733802, 2014CB744503), National Science Foundation of China (NSFC) (81301257, 81301256, 81371596), and the Intramural Research Program (IRP) of the National Institute of Biomedical Imaging and Bioengineering (NIBIB), NCI), National Institutes of Health (NIH).

\section{Competing Interests}

The authors have declared that no competing interest exists.

\section{References}

1. Josefsen LB, Boyle RW. Unique diagnostic and therapeutic roles of porphyrins and phthalocyanines in photodynamic therapy, imaging and theranostics. Theranostics. 2012; 2: 916-66. doi:10.7150/thno.4571.

2. Dolmans D, Fukumura D, Jain RK. Photodynamic therapy for cancer. Nat Rev Cancer. 2003; 3: 380-7.

3. Agostinis P, Berg K, Cengel KA, Foster TH, Girotti AW, Gollnick SO, et al. Photodynamic therapy of cancer: an update. CA Cancer J Clin. 2011; 61: 250-81. doi:10.3322/caac. 20114

4. Vrouenraets MB, Visser GW, Stigter M, Oppelaar H, Snow GB, van Dongen GA. Targeting of aluminum (III) phthalocyanine tetrasulfonate by use of internalizing monoclonal antibodies: improved efficacy in photodynamic therapy. Cancer Res. 2001; 61: 1970-5.

5. Zheng G, Graham A, Shibata M, Missert JR, Oseroff AR, Dougherty TJ, et al. Synthesis of beta-galactose-conjugated chlorins derived by enyne metathesis as galectin-specific photosensitizers for photodynamic therapy. J Org Chem. 2001; 66: 8709-16.

6. Vrouenraets MB, Visser GW, Stigter M, Oppelaar H, Snow GB, van Dongen GA. Comparison of aluminium (III) phthalocyanine tetrasulfonate- and meta-tetrahydroxyphenylchlorin-monoclonal antibody conjugates for their efficacy in photodynamic therapy in vitro. Int J Cancer. 2002; 98: 793-8.
7. Zheng X, Pandey RK. Porphyrin-carbohydrate conjugates: impact of carbohydrate moieties in photodynamic therapy (PDT). Anticancer Agents Med Chem. 2008; 8: 241-68.

8. Mitsunaga M, Ogawa M, Kosaka N, Rosenblum LT, Choyke PL, Kobayashi H. Cancer cell-selective in vivo near infrared photoimmunotherapy targeting specific membrane molecules. Nat Med. 2011; 17: 1685-91. doi:10.1038/nm.2554.

9. Wang S, Fan W, Kim G, Hah HJ, Lee YE, Kopelman R, et al. Novel methods to incorporate photosensitizers into nanocarriers for cancer treatment by photodynamic therapy. Lasers Surg Med. 2011; 43: 686-95. doi: $10.1002 / 1 \mathrm{sm} .21113$

10. Gupta A, Wang S, Pera P, Rao KV, Patel N, Ohulchanskyy TY, et al. Multifunctional nanoplatforms for fluorescence imaging and photodynamic therapy developed by post-loading photosensitizer and fluorophore to polyacrylamide nanoparticles. Nanomedicine (Lond). 2012; 8: 941-50. doi:10.1016/j.nano.2011.11.011.

11. Samia AC, Chen X, Burda C. Semiconductor quantum dots for photodynamic therapy. J Am Chem Soc. 2003; 125: 15736-7. doi:10.1021/ja0386905.

12. Samia AC, Dayal S, Burda C. Quantum dot-based energy transfer: perspectives and potential for applications in photodynamic therapy. Photochem Photobiol. 2006; 82: 617-25. doi:10.1562/2005-05-11-IR-525.

13. Cheng Y, A CS, Meyers JD, Panagopoulos I, Fei B, Burda C. Highly efficient drug delivery with gold nanoparticle vectors for in vivo photodynamic therapy of cancer. J Am Chem Soc. 2008; 130: 10643-7. doi:10.1021/ja801631c.

14. Peng J, Zhao L, Zhu X, Sun Y, Feng W, Gao Y, et al. Hollow silica nanoparticles loaded with hydrophobic phthalocyanine for near-infrared photodynamic and photothermal combination therapy. Biomaterials. 2013; 34: 7905-12.

15. Lin J, Wang S, Huang P, Wang Z, Chen S, Niu G, et al. Photosensitizer-loaded gold vesicles with strong plasmonic coupling effect for imaging-guided photothermal/photodynamic therapy. ACS Nano. 2013; 7: 5320-9. doi:10.1021/nn4011686.

16. Lovell JF, Jin CS, Huynh E, Jin H, Kim C, Rubinstein JL, et al. Porphysome nanovesicles generated by porphyrin bilayers for use as multimodal biophotonic contrast agents. Nat Mater. 2011; 10: 324-32. doi: $10.1038 /$ nmat2986.

17. Tian B, Wang C, Zhang S, Feng L, Liu Z. Photothermally enhanced photodynamic therapy delivered by nano-graphene oxide. ACS Nano. 2011; 5: 7000-9.

18. Huang $\mathrm{P}, \mathrm{Xu} \mathrm{C}$, Lin J, Wang C, Wang $\mathrm{X}$, Zhang C, et al. Folic acid-conjugated graphene oxide loaded with photosensitizers for targeting photodynamic therapy. Theranostics. 2011; 1: 240-50.

19. Ethirajan $\mathrm{M}$, Chen $\mathrm{YH}$, Joshi $\mathrm{P}$, Pandey RK. The role of porphyrin chemistry in tumor imaging and photodynamic therapy. Chem Soc Rev. 2011; 40: 340-62.

20. Srivatsan A, Ethirajan M, Pandey SK, Dubey S, Zheng X, Liu TH, et al. Conjugation of cRGD peptide to chlorophyll a based photosensitizer (HPPH) alters its pharmacokinetics with enhanced tumor-imaging and photosensitizing (PDT) efficacy. Mol Pharm. 2011; 8: 1186-97.

21. Bellnier DA, Greco WR, Nava H, Loewen GM, Oseroff AR, Dougherty TJ. Mild skin photosensitivity in cancer patients following injection of Photochlor (2-[1-hexyloxyethyl]-2-devinyl pyropheophorbide-a; HPPH) for photodynamic therapy. Cancer Chemother Pharmacol. 2006; 57: 40-5. doi:10.1007/s00280-005-0015-6.

22. Bitounis D, Ali-Boucetta H, Hong BH, Min D-H, Kostarelos K. Prospects and Challenges of Graphene in Biomedical Applications. Adv Mater. 2013; 25: 2258-68: DOI: 10.1002/adma.201203700.

23. Feng LZ, Liu ZA. Graphene in biomedicine: opportunities and challenges. Nanomedicine. 2011; 6: 317-24.

24. Feng L, Zhang S, Liu Z. Graphene based gene transfection. Nanoscale. 2011; 3: $1252-7$

25. Yang X, Wang Y, Huang X, Ma Y, Huang Y, Yang R, et al. Multi-functionalized graphene oxide based anticancer drug-carrier with dual-targeting function and pH-sensitivity. J Mater Chem. 2011; 21: 3448-54.

26. Ma X, Tao H, Yang K, Feng L, Cheng L, Shi X, et al. A functionalized graphene oxide-iron oxide nanocomposite for magnetically targeted drug delivery, photothermal therapy, and magnetic resonance imaging. Nano Res. 2012; 5: 199-212.

27. Zhang SA, Yang K, Feng LZ, Liu Z. In vitro and in vivo behaviors of dextran functionalized graphene. Carbon. 2011; 49: 4040-9.

28. Yang K, Zhang S, Zhang G, Sun X, Lee S-T, Liu Z. Graphene in Mice: Ultra-high in vivo Tumor Uptake and Photothermal Therapy. Nano Lett. 2010; 10: 3318-23

29. Yang $\mathrm{K}$, Feng $\mathrm{L}$, Shi $\mathrm{X}$, Liu Z Nano-graphene in biomedicine: theranostic applications. Chem Soc Rev. 2013; 42: 530-47.

30. Shi S, Yang K, Hong H, Valdovinos HF, Nayak TR, Zhang Y, et al. Tumor vasculature targeting and imaging in living mice with reduced graphene oxide. Biomaterials. 2013; 34: 3002-9.

31. Shi X, Gong H, Li Y, Wang C, Cheng L, Liu Z. Graphene-based magnetic plasmonic nanocomposite for dual bioimaging and photothermal therapy. Biomaterials. 2013; 34: 4786-93.

32. Shen H, Zhang L, Liu M, Zhang Z. Biomedical applications of graphene. Theranostics. 2012; 2: 283-94. doi:10.7150/thno.3642.

33. Zhang L, Xia J, Zhao Q, Liu L, Zhang Z. Functional graphene oxide as a nanocarrier for controlled loading and targeted delivery of mixed anticancer Drugs. Small. 2010; 6: 537-44. 
34. Sun X, Liu Z, Welsher K, Robinson JT, Goodwin A, Zaric S, et al. Nano-graphene oxide for cellular imaging and drug delivery. Nano Res. 2008; 1: 203-12.

35. Liu Z, Robinson JT, Sun XM, Dai HJ. PEGylated nanographene oxide for delivery of water-insoluble cancer drugs. J Am Chem Soc. 2008; 130: 10876-7.

36. Wang Y, Wang K, Zhao J, Liu X, Bu J, Yan X, et al. Multifunctional mesoporous silica-coated graphene nanosheet used for chemo-photothermal synergistic targeted therapy of glioma. J Am Chem Soc. 2013; 135: 4799-804.

37. Yang K, Wan J, Zhang S, Tian B, Zhang Y, Liu Z. The influence of surface chemistry and particle size of nanoscale graphene oxide on photothermal therapy of cancer using ultra-low laser power. Biomatreials. 2012; 33: 2206-14.

38. Wen H, Dong C, Dong H, Shen A, Xia W, Cai X, et al. Engineered redox-responsive PEG detachment mechanism in PEGylated nano-graphene oxide for intracellular drug delivery. Small. 2012; 8: 760-9.

39. Duch MC, Budinger GR, Liang YT, Soberanes S, Urich D, Chiarella SE, et al. Minimizing oxidation and stable nanoscale dispersion improves the biocompatibility of graphene in the lung. Nano Lett. 2011; 11: 5201-7. doi:10.1021/nl202515a.

40. Yang K, Wan JM, Zhang SA, Zhang YJ, Lee ST, Liu Z. In vivo pharmacokinetics, long-term biodistribution, and toxicology of PEGylated graphene in mice. ACS Nano. 2011; 5: 516-22.

41. Yang K, Gong H, Shi X, Wan J, Zhang Y, Liu Z. Invivo biodistribution and toxicology of functionalized nano-graphene oxide in mice after oral and intraperitoneal administration. Biomaterials. 2013; 34: 2787-95.

42. Shi J, Liu TW, Chen J, Green D, Jaffray D, Wilson BC, et al. Transforming a targeted porphyrin theranostic agent into a PET imaging probe for cancer. Theranostics. 2011; 1: 363-70.

43. Semisotnov GV, Rodionova NA, Razgulyaev OI, Uversky VN, Gripas AF, Gilmanshin RI. Study of the "molten globule" intermediate state in protein folding by a hydrophobic fluorescent probe. Biopolymers. 1991; 31: 119-28. doi:10.1002/bip.360310111.

44. Zheng X, Morgan J, Pandey SK, Chen Y, Tracy E, Baumann H, et al. Conjugation of 2-(1'-hexyloxyethyl)-2-devinylpyropheophorbide-a (HPPH) to carbohydrates changes its subcellular distribution and enhances photodynamic activity in vivo. J Med Chem. 2009; 52: 4306-18. doi:10.1021/jm9001617.

45. Feng L, Yang X, Shi X, Tan X, Peng R, Wang J, et al. Polyethylene glycol and polyethylenimine dual-functionalized nano-graphene oxide for photothermally enhanced gene delivery. Small. 2013; 9: 1989-97. doi:10.1002/smll.201202538. 